\title{
Explanatory models of families of children with type 1 diabetes mellitus
}

\author{
Modelos explicativos das famílias de crianças com diabetes mellitus tipo 1 \\ Modelos explicativos de las familias de niños con diabetes mellitus tipo 1
}

Isa Ribeiro de Oliveira Dantas'
ORCID: 0000-0003-0384-5175

Rhyquelle Rhibna Neris"

ORCID: 0000-0001-7796-4025

Márcia Maria Fontão Zago"

ORCID: 0000-0001-6539-2584

Manoel Antônio dos Santos"

ORCID: 0000-0001-8214-7767

Lucila Castanheira Nascimento"

ORCID: 0000-0002-7900-7111

'Centro Universitário de Patos de Minas. Patos de Minas, Minas Gerais, Brazil.

"Universidade de São Paulo. Ribeirão Preto, São Paulo, Brazil.

How to cite this article:

Dantas IRO, Neris RR, Zago MMF, Santos MA,

Nascimento LC. Explanatory models of families

of children with type 1 diabetes mellitus.

Rev Bras Enferm. 2020;73(Suppl 4):e20180975. doi: http://dx.doi.org/10.1590/0034-7167-2018-0975

Corresponding author:

Isa Ribeiro de Oliveira Dantas

E-mail: informar: isa@unipam.edu.br

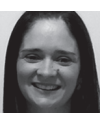

EDITOR IN CHIEF: Antonio José de Almeida Filho ASSOCIATE EDITOR: Italo Rodolfo Silva

Submission: $02-10-2019$

Approval: 04-23-2020

\begin{abstract}
Objectives: to analyze how children with type 1 diabetes mellitus and their families explain the pathology, based on their understanding of the factors related to the discovery of diabetes, the etiology, treatment, and prognosis of the disease. Methods: qualitative methodological approach, based on medical anthropology and the narrative method. In-depth interviews were conducted with 12 families of children with type 1 diabetes mellitus attending follow-up consultations at a specialized center. The statements were subjected to inductive thematic analysis. Results: the explanatory models identified describe the families search for the clarification of the signs and symptoms that the child had. Faced with the disease, families reorganized themselves to meet new health care needs of children, such as adequate nutrition, physical exercise, and blood glucose monitoring. Final Considerations: knowing the explanatory models allows the understanding of how families give meaning to the child's illness, favoring daily nursing care and an effective control of the disease.

Descriptors: Family; Diabetes Mellitus, Type 1; Pediatric Nursing; Anthropology, Medical; Qualitative Research.
\end{abstract}

\section{RESUMO}

Objetivos: analisar como crianças com diabetes mellitus tipo 1 e suas famílias explicam a patologia, a partir da compreensão que possuem sobre os fatores relacionados à descoberta do diabetes, etiologia, tratamento e prognóstico da doença. Métodos: abordagem metodológica qualitativa, fundamentada na antropologia médica e método narrativo. Realizaram-se entrevistas em profundidade com 12 famílias de crianças com diabetes mellitus tipo 1 em seguimento em um centro especializado. Submeteram-se as narrativas à análise temática indutiva. Resultados: os modelos explicativos identificados descrevem a busca das famílias pelo esclarecimento dos sinais e sintomas que a criança apresentava. Diante da doença, as famílias se reorganizaram para atender às novas necessidades de cuidados de saúde das crianças, como alimentação adequada, prática de exercícios físicos e monitorização glicêmica. Considerações Finais: conhecer os modelos explicativos permite compreender como as famílias dão sentido à experiência do adoecimento da criança, favorecendo o cuidado diário de enfermagem e o efetivo controle da doença.

Descritores: Família; Diabetes Mellitus Tipo 1; Enfermagem Pediátrica; Antropologia Médica; Pesquisa Qualitativa.

\section{RESUMEN}

Objetivos: analizar como niños con diabetes mellitus tipo 1 y sus familias explican la patología, a partir de la comprensión que poseen sobre los factores relacionados a la descubierta del diabetes, etiología, tratamiento y pronóstico de la enfermedad. Métodos: abordaje metodológico cualitativo, fundamentado en la antropología médica y método narrativo. Se han realizado entrevistas en profundidad con 12 familias de niños con diabetes mellitus tipo 1en seguimiento en un centro especializado. Se ha sometido las narrativas al análisis temático inductivo. Resultados: los modelos explicativos identificados describen la búsqueda de las familias por el esclarecimiento de los señales y síntomas que el niño presentaba. Delante de la enfermedad, las familias se reorganizaron para atender a las nuevas necesidades de cuidados de salud de los niños, como alimentación adecuada, práctica de ejercicios físicos y seguimiento glucémico. Consideraciones Finales: conocer los modelos explicativos permite comprender como las familias ha dado sentido a la experiencia de la enfermedad del niño, favoreciendo el cuidado diario de enfermería y el efectivo control de la enfermedad.

Descriptores: Familia; Diabetes Mellitus Tipo 1; Enfermería Pediátrica; Antropología Médica; Investigación Cualitativa. 


\section{INTRODUCTION}

Type 1 diabetes mellitus (DM1) is a chronic condition, associated with several metabolic disorders that can compromise the quality of life of both the sick child and their family members. This happens especially due to the many responsibilities and to the discipline required to face the care demands by all those involved ${ }^{(1)}$.

The diagnosis of DM1 causes numerous changes in the daily life of the children and their family, mainly because it is a new and challenging situation. Over time, they become better acquainted with the disease and, depending on social support and on the assistance received, they can lead a more balanced life, ensuring the continuity of adequate growth and development for children with diabetes ${ }^{(2)}$.

When observing a family that lives with a child with DM1, it is clear that not only does the child feel the challenges of managing the disease, but also all the people who make up their personal network start to experience this new reality ${ }^{(3)}$. The family usually changes its activities, aiming to maximize the well-being of the child with diabetes. This tends to favor the treatment and monitoring of the chronic disease, since the changes caused by the diagnosis of DM1 are inevitable ${ }^{(4)}$. The diagnosis of a chronic disease triggers conflicts, fear, insecurity and, often, family overprotection, which can compromise the child's development in critical periods for the constitution of her/his identity ${ }^{(5)}$.

Faced with a disease, health professionals, patients and their families develop a framework for the interpretation of the changes and disorders observed, whose meanings must be sought in the interpretation systems with which they are associated ${ }^{(6)}$. According to this perspective, the disease is not an entity, but an explanatory model. Explanatory models (EMs) are understood as cultural models that organize and structure the experiences of people with a disease, in order to make sense both for them and for those who are part of their family circle, transforming it, therefore, in a cultural experience ${ }^{(7)}$.

The types of EMs are classified as professional and popular. Professional EMs are elaborated by health professionals and have a scientific bases, while popular EMs are based on the culture shared and experienced by all members of a certain group. The popular EM shows the meaning attributed to health and disease by the patient and his family, as well as the expected results with the treatment. They are used by individuals to explain, organize and cope with the disease, being consistently influenced by personality and cultural factors, and characterized by a variety of meanings, imprecision, frequent changes and the absence of defined boundaries between ideas and experience. In contrast, professional EMs are based on scientific coherence $\mathrm{e}^{(7-8)}$.

To develop a convincing explanation for the disease, it is not necessary to resort to medical knowledge, address triggering factors, or have experience in modern diagnostic techniques. The experience of the disease alone demonstrates part of the social world of those who experience it. Considering these assumptions, this study seeks to understand the meanings attributed to the disease based on socially shared personal experiences ${ }^{(9)}$.

To systematize and analyze the way children with DM1 and their families deal with this chronic illness and organize their experiences, the theoretical basis of EMs was used. This method allows the understanding that the illness can be interpreted and defined in different ways, according to the meanings assigned. The popular EM was used specifically to find the point of view of the disease from of children with DM1 and their families, through the construction of their narratives from the interviews.

\section{OBJECTIVES}

To analyze how children with type 1 diabetes mellitus (DM1) and their families explain the pathology, based on their understanding of the factors related to the discovery of diabetes, as well as the etiology, treatment, and prognosis of the disease.

\section{METHODS}

\section{Ethical aspects}

The present study was approved by the Research Ethics Committee of the proposing and co-participating institution. In compliance with ethical norms, through clear and objective language, the participants were informed about the research objectives and were assured of confidentiality regarding their identities using fictitious names. After accepting the invitation, parents and family members signed the Free and Informed Consent Form; and for the children with DM1 and their siblings over seven years old they signed the Free and Informed Consent Form. Fictitious names for children with diabetes were made according to the first letter of the child's real name, and their family members were identified according to the degree of kinship.

\section{Theoretical-methodological framework and study design}

This is a study with a qualitative methodological approach, based on the theoretical framework of medical anthropology. As a strategy to organize the information that make up the EMs of the group of families participating in this study and as a way of valuing the people and stories of the families of children with DM1, the narrative method was used. The narratives of the disease provide information on how life problems are created, controlled, and signified ${ }^{(10)}$.

Medical anthropology seeks to understand how beliefs and practices are related to biological, psychological, and social changes in the human organism, both in health and in disease. In this context, it is understood that the families of children with DM1 are influenced by the cultural environment in which they live. Culture refers to the set of meanings related to the context in which the processes of signification occur; it is projected by the subject and experienced by the social group and constitutes a support for the actions of its members, influencing and structuring the way in which they act, react, perceive and organize the world where they live ${ }^{(8,11)}$.

\section{Place of study and data source}

Children with DM1 and their families who were being attended for follow-up consultations in a care center specialized in 
systemic arterial hypertension and diabetes mellitus were invited to collaborate with the research. This center is in the interior of the state of Minas Gerais. For the purposes of this investigation, family members were defined as those individuals involved in the care of the child and responsible for their monitoring and follow-up in the health service, particularly parents, mothers or other adult caregivers, linked to the child by ties of affinity or consanguinity. In addition, the siblings of children with DM1 over seven years old were invited to participate in the research.

The criteria established for the selection of children were up to 12 years old and residing in the municipality where the specialized center is located. The age group of up to 12 years of age was chosen in accordance to the definition contained in the Child and Adolescent Statute (ECA), which considers children, for the purposes of the law, as those up to 12 incomplete years of age ${ }^{(12)}$. The families were recruited in the waiting room by the researcher, while waiting for the child's consultation with health professionals. The researcher responsible for data collection was not regularly involved in activities carried out at the health service in which children with DM1 were recruited, thus not characterizing an authoritative relationship with participants.

\section{Data collection}

In-depth interviews were conducted by the first author, who is a nurse and has previous experience in collecting qualitative data. In addition to the interview, family access tools were used, such as a genogram and an ecomap, which are valuable strategies for interaction between the interviewer and family members, including children. Through in-depth interviews and the use of these tools, family members and children had complete freedom to express themselves and, given the researcher's sensitivity and the need to go in-depth with regards to certain aspects, new questions were asked. All interviews with families were carried out at home and supported by a script, which contained the following questions: "How was the child's diabetes discovered? Why do you think the child has diabetes? And what does your family think about it? How was it for you to receive the diagnosis? And for your family? What would you like to tell me about the treatment of the disease? What else do you use to treat diabetes? Do you and your family believe in a cure for diabetes? What did the child's diabetes mean to your family? What has helped your family to deal with childcare? What does your family expect for the child's future? Does anyone think differently?"In addition, information considered relevant to the reflection were recorded in the field diary — for example, those related to the environment and family interaction. The first interview, with the three families initially included, also had the objective of verifying the adequacy of the interviews guiding script, which proved to be adequate to address the phenomenon of interest.

The length of stay in the field was from January 2012 to December 2014. A total of 12 families of children with DM1 were invited to participate in the study and all accepted the invitation, and no family member refused to participate in the research. For each family, interviews were conducted with the children and three family members (father, mother, and another adult caregiver). A minimum of four and a maximum of six interviews were conducted with each family. The interviews were conducted individually or in groups, according to the availability of the families and, in certain situations, complying with the participants' desire to share other information with the main researcher. In total, 58 meetings were held with families in their homes, with an average duration of 90 minutes each meeting. Data collection and analysis took place simultaneously. The recruitment of 12 families allowed a clear understanding of the phenomenon and determined the end of data collection.

\section{Data analysis}

The data collection process and data analysis were simultaneous. All interviews were recorded in audio, with the consent of the participants and, later, transcribed in full. Subsequently, the transcriptions of the interviews were reviewed by the first author, with supervision by the last co-author, the research supervisor, to compare the text with the recorded audio, followed by reading, re-reading, and surveying the main ideas for the construction of each family narrative.

For the analysis of the narratives, the inductive thematic analysis was used. The following steps were taken: 1 ) review of narratives, rereading and survey of initial ideas; 2 ) elaboration of the initial codes, with organization in sequence, which would make it possible to recognize significant and common aspects of the data and transform them into narrative texts; 3 ) search for themes, in which the meanings expressed through the narratives were organized in order to start the construction of a theme-essence; 4) checking and refining the themes; 5 ) presentation of the narrative synthesis of the experiences of the families of children with $\mathrm{DM}^{(13)}$.

\section{RESULTS}

Twelve families of children with DM1 (Geovane, Eduarda, Alexandre, Yara, Débora, Vanessa, Gabriel, Larissa, Giovana, Renata, Marcos, and Adriana), participated in this study, totaling 51 participants. Table 1 presents the characteristics of the families.

Table 1 - Characterization of the families included in the study, Patos de Minas, Minas Gerais, Brazil

\begin{tabular}{lc}
\hline Characteristics & $\mathbf{n}$ \\
\hline Participants & \\
Children & 12 \\
Mother & 12 \\
Father & 10 \\
Brother & 10 \\
Aunt & 4 \\
Grandfather & 3 \\
Age of the children & \\
5-7 years & 2 \\
8-9 years & 3 \\
10-11 years & 7 \\
Age of the family members & \\
Up to 19 years & 8 \\
20-30 years & 2 \\
31-40 years & 13 \\
41-50 years & 10 \\
51-60 years & 4 \\
61-75 years & 2 \\
Family members educational level & \\
None & 2 \\
Elementary school & 15 \\
High school & 18 \\
College education & 4 \\
\hline
\end{tabular}


In terms of the organization of the participating families, nine are considered nuclear families, two children had divorced parents, and the parent of one child was single.

\section{Search for explanations for the child's behavioral and physical changes}

Many families have discovered the child's illness due to the appearance of some signs and symptoms; in addition, the certainty that something was not going well made them seek assistance to clarify the child's health situation. In the following narrative fragments, family members report how they perceived the appearance of the first signs and symptoms in the child:

When the symptoms started, she started drinking a lot of water and, since she was at school, the teacher called me. She drank almost two liters of water at night, and that was for about 20 days. Since the teacher complained, I soon asked to take the glucose test. I did not imagine that a child could have diabetes, there was never a person with diabetes in my family, I did not even imagine. I ordered it because I could have high glucose, not to have to use insulin, change the whole routine. When I took her, my daughter was already diabetic, with very high glucose levels. (Yara's mother)

My daughter started with weight loss, she got weak, was unable to walk. When she arrived at the hospital, she did not speak for four days. They did all kinds of tests, they even did an HIV test. She lost fifteen pounds in a month. Everyone was disoriented; it was very strange. (Renata's mother)

In the context of this study, when receiving the diagnosis of DM1, families and sick children reacted in different ways. Fear, anxiety, and sadness were the main emotions reported, in addition to the perplexity and initial shock caused by ignorance about the disease. These feelings are evidenced in the statements bellow:

[...] As my son developed diabetes at the age of one and a half, at the time you become numb, you don't even know exactly what you are going through, what will happen. You don't know anything, you have to learn by yourself. [...] As I was not aware of the disease, I think I was without action, stunned, I had no reaction at all. I didn't cry or laugh, I stood still, I didn't do anything. Then we think: "My God, why?" (Alexandre's mother)

Receiving my son's diagnosis of diabetes was a shock, a big change. We were not prepared, there was nothing to justify it and, suddenly, in a routine consultation, the doctor ordered the test and before the test result was ready, they called me to ask if I knew he was diabetic. It was a very big surprise. I didn't blame myself, I didn't look for reasons, but my wife got a little lost. My reasoning was more logical, it happened as it happens in other places, with other families and with other children. With my son it was at two years old; there are children to whom it happens even earlier. (Gabriel's father)

The popular EM, related to the diagnosis of children with DM1, showed that many families were unaware of the disease, which consequently hindered their acceptance, complicated the management of symptoms, and delayed the start of treatment, as illustrated by the selected statements from the narratives:
I began to think that my daughter had anemia or an infection. It took me a while to get help, but since I had no idea what diabetes was, I took her to the doctor. (Débora's mother)

When I found out, I had no idea what diabetes was. For me, diabetes was an old people's disease; I didn't even know that a child could have diabetes. (Alexandre's mother)

In the search for explanations regarding the chronic disease, families attributed the child's condition to several factors. One of the factors pointed out in the reports, refers to the genetic or hereditary factor:

I think my daughter had diabetes because of her genetic. I already asked several doctors and they all said that it's genetic. (Vanessa's mother)

I believe that the cause of diabetes is hereditary. There are people who say it is not hereditary, but I've heard it's. The grandfather, father of his father [grandson], has it. I believe it's hereditary. (Alexandre's grandmother)

The physiological factor, more specifically, an organ dysfunction was observed in the narrative of a family member:

[...] I think what happened to my sister was the lack of insulin in her blood. They say it was genetic, but she has it and no one else in the family did. But after she had it, my grandfather also had it [...] (Débora's sister)

Other factors, such as unbalanced eating and emotional organization, were also reported by family members, which reinforces the popular EM as a way of explaining the disease:

Perhaps the illness was caused by an emotional factor, but I don't know. At the time of the diagnosis, I had been transferred to another city and my son and wife did not go with me. (Gabriel's father)

I don't know very well what caused my daughter's diabetes, I didn't think much. I think it may have been the food; sometimes, I believe that I may have had gestational diabetes. During pregnancy, it may have passed to her. (Yara's mother)

Children with DM1 also elaborate explanations for their disease. Their knowledge is acquired through family, friends, and other sources of information:

I think I have diabetes because my pancreas stopped working. I don't know much about diabetes. I just know that the person who has diabetes cannot eat too much candy. (Gabriel)

I don't know why I have diabetes. I think it's because my pancreas doesn't work anymore, it doesn't produce insulin. (Alexandre)

The EM referring to the diagnosis of diabetes in children is strongly linked to cultural factors related to the reaction to its discovery by family and friends. The meanings constructed for signs and symptoms, including changes in body image, are also influenced by the cultural context in which the disease occurs. For example, culturally, for our society, sudden weight loss indicates 
that something is not going well with the body, which is usually understood as a sign that it is necessary to seek medical help.

\section{Life with diabetes: proposals from children and their families to control the disease and its symptoms}

The popular EM related to the treatment and the expected results with the use of methods to control the disease showed that families know the traditionally established therapy and its mechanisms of action Aiming at an adequate management of diabetes. Particularly, families recognize the importance of maintaining adequate eating habits, to do physical exercise and to monitor blood glucose.

[...] she has to take insulin, to exercise and go on a diet. It is a disease that the pancreas will not produce insulin, glucose will not be able to be eliminated and then she cannot eat sweets, because otherwise it cannot be eliminated. (Renata's sister)

I think what is essential in the treatment is the diet. My daughter was exercising, and it did not lower the glucose, the control was not $100 \%$. There are people who say that exercise is very good, but what I think helps most is to follow the right diet and associate it with exercise. (Débora's mother)

The narratives reveal that, in face of the child's illness, there was a reorganization of the eating habits of the whole family:

[...] The whole family, everyone went into despair. Everyone just cried, everyone was on a candy diet. Even at my sisters' house, nobody could eat sweets, because my daughter liked it too much. How could our consciousness allow us to eat candy when she can't? Everyone was on a diet, everyone was crying, my father cried, my mother cried. (Yara's mother)

In the fragments of the following narratives, the difficulties related to treatment were mentioned by some children and their families. Specially the maintenance of an adequate diet for the control of diabetes and the use of needles for the control of blood glucose and for the application of insulin. Families reported that the disease brought a certain limitation to the entire family system, causing the deprivation of some activities that were usual before the disease:

What I find most difficult is not being able to eat what we want. The diet is very difficult to follow. Eating vegetables every day, drinking yogurt, getting sick. It's very difficult for me to eat pasta, but the day l eat it, I don't eat potatoes. (Alexandre)

What I find most difficult in treatment is having to keep taking the glucose test every day. I do the glucose control myself. I do it every morning and night, before going to bed, or when I feel bad. (Gabriel)

What I find most difficult in my daughter's situation is that she enjoys things a little less than the other children. She doesn't stop enjoying it, but she has some limits. For example, when she is playing, running, she has to stop playing to measure glucose, to see how she is doing, to take insulin, and that sucks. It is not bad to do, but it sucks for her. (Vanessa's father)

Parallel to the biomedical model, in the search for effective control of the disease, as a way to alleviate the symptoms, especially those related to hyperglycemia, families resort to the popular model, and use complementary methods for the treatment of the child's DM1. Often, neighbors and family members are primarily responsible for providing this information that supplies popular EMs. Families are aware that it is a complementary therapy, not a substitute or alternative method, as patients with DM1 are totally dependent on daily insulin doses to achieve effective control of the disease:

[...] There is a little insulin plant in the yard and I'm taking care of it. If there is a potato that is good for insulin, I use it. Everything they say is good for diabetes, I try to use it. The passion fruit powder, my daughter uses it, we always put in food. I use in parallel with the insulin; it doesn't change her routine, it just complements it. The only thing I do, with medical advice, is that if the glucose goes down, I lower the dose. If it goes up, I increase the dose. (Yara's mother)

We have already used banana flour in the treatment. We try everything they say is good, as long as it does not interfere and harm. (Vanessa's father)

The popular EMs related to the prognosis of the disease demonstrate the hope of families of children with DM1 for a cure, the perspectives regarding the evolution of the disease and the expectations regarding the future of the child who lives with this chronic condition. Most families hope to achieve the child's cure. These families hold on to this belief as a way of easing the pain and suffering imposed by the disease. Some families believe in the cure, but do not know how it will happen; other families, through acquired information, are able to envisage more precise and calculated solutions for obtaining a cure for the child's disease, as shown by the fragment of the following narrative:

I believe that at some point the cure for diabetes will appear and I hope it arrives in time for my child. About pancreatic transplantation, for example, I am sad when I see researches showing that the pancreas is one of the most difficult organs to adapt. But, if I have a guarantee from doctors that the transplant will work, I will want my son to do it, I will try. (Gabriel's father)

I hope that one day a cure can happen. I read some recent information about what doctors are doing with stem cells. In recent years, some families that have good financial conditions are already keeping stem cells, thinking about it, but if this is the cure, for my daughter it isn't. (Larissa's mother)

Expectations regarding the evolution of the disease and the future of the child with DM1 can be seen in the fragments of the narratives bellow. Families expect the best for their children, even though they know that it is a chronic disease and that the necessary care for a good evolution must be followed properly, so that the prognosis is favorable:

His future, I think it will be bright. He will live with diabetes and will know how to deal with it. We want to do our best for him. I am not afraid that something will happen to my son. There will come a point that it will be just him, other people who will no longer take care of it, and I hope he has the future he chooses. Forme, he is my son, and he was born to shine. He is a very intelligent boy, very capable, shy, but very intelligent. I am impressed by his maturity and his creative ability. He sometimes surprises me. He has some very ingenious thoughts 
that bring me back to when I was younger. I didn't have as much as he does today. I didn't even dare to ask my father; sometimes, I went out and invented a contraption and it worked. (Gabriel's father)

When I grow up, I want to be an endocrinologist, because I have diabetes and I want to help other children. (Débora)

The popular EM associated with the prognosis showed the main factors raised by the families regarding the expectations about the child's chronic disease. The beliefs about the supposed cure and, at the same time, the uncertainty regarding its feasibility were explored in the reports produced.

\section{DISCUSSION}

Experiencing chronic illnesses is a difficult burden to be immediately accepted by children and their families. An illness, as a possible human event, is devastating in its emergence. It destroys dreams, projects, and hopes that parents have for the future of their children. The reactions of shock, surprise and perplexity when receiving the diagnosis of DM1 show that the participants find themselves immersed in feelings of strangeness when perceiving themselves face to face with the unknown. For this reason, they present, in most cases, an exacerbation of the feeling of helplessness and disorientation ${ }^{(14-15)}$. Upon discovering the chronic illness of their children, families are faced with doubts, uncertainties, feelings of revolt and despair. This situation mobilizes them to seek explanations to better understand this disease in order to mitigate the feeling of insecurity and fragility caused by the rupture and loss of references of normality. In addition, they search solutions that can minimize the suffering and the restrictions of personal freedom, such as the limitations imposed on the daily life of the child and the rest of the family ${ }^{(16)}$.

It is inevitable that changes in family life occur after the diagnosis of the disease. The family, in most cases, radically changes certain habits due to the child with diabetes, which can increase tensions and discomfort in intrafamilial relationships. With the treatment, there is a reorganization of family functioning, which seeks to restore the lost balance. There are also changes in the tasks performed by caregivers, since now parents must go after resources for treatment ${ }^{(14)}$.

In addition to physical overload, there is a significant financial impact on families, which occurs just when the family focus was focused in meeting the specific needs of young children. Thus, changes in the daily lives of families with children are very evident. Among the most significant changes are the eating habits, daily monitoring of blood glucose, and adjustments to the dose of insulin. Families seek to restructure the food routine before the diagnosis, and as a result, changing behaviors in relation to the diet and subjecting the family unit to dietary reeducation ${ }^{(17)}$.

Living with DM1 is a journey of learning and adapting. This disease is a condition that requires strict discipline and compliance with standards prescribed by the treatment plan. As family members and patients in this study acknowledge, treatment consists in following a standardized scheme which, sometimes, has little flexibility to admit variations. Communication between parents and health professionals is essential to facilitate adaptation and protect the development of children with DM1, thus favoring independence and gradual autonomy. Parents and health professionals are essential agents to ensure favorable environments for the child's development, in addition to having an important role in social support ${ }^{(18)}$.

The same disease or symptom can be interpreted completely differently by individuals who are in different cultures and contexts. Some signs and symptoms were referred by the families as evidence of the manifestation of the disease. One of the most obvious signs reported by family members was sudden weight loss. The body is more than just a physical organism that alternates between health and disease. It is part of a set of beliefs and values about its own social and psychological meaning, its structure and function. Body image is a representation elaborated by the individual as part of the growth in each family, culture, or society. Even though there are many variations in body image within each group ${ }^{(8)}$.

Families attributed several causes for the development of DM1 in their children, including diet, and physiological, hereditary, and emotional factors. Heredity is a relevant explanatory factor not only for individual talents, intelligence, and character traits, but also for the enigmatic emergence of the disease. Genetics provide evidence that there is a shared biological heritage. Therefore, popular knowledge about heredity should be considered in relation to information on disorders or risk factors inherited by individuals ${ }^{(8)}$.

The etiologies of certain diseases are based on a system of beliefs and values about the structure and function of the organism, as well as about the ways in which it can work. Even when they are based on scientifically incorrect definitions, these lay models often show a remarkable coherence and consistency that, frequently, helps the person with the pathology to elaborate a sense of what happened and why it occurred ${ }^{(8)}$

To demystify prejudices and indicate the best way to care and live constructively with the disease, it is extremely important to assess previous knowledge and discuss it with the child and the family. The use of creative strategies in the communication established between health professionals and the child facilitates the expression of feelings and experiences with important meanings with regards to care. These strategies favor the feeling of being welcomed and respected in their affective needs ${ }^{(2)}$.

Children develop their own understanding of pathology, etiopathogenesis, and of how the disease should be treated. Like adults, they look for explanations of why and how that happened to them and why it did at that specific time. Their EMs are usually a variation of ideas originating from personal experience and the influence of family, school, and the media(8).

At the beginning of the diagnosis of DM1, a temporal rupture can be noticed, resulting in two stages: before and after the child's diagnosis. This makes the family face irreversible situations inherent to the disease and leads to a permanent surveillance for perceiving the signs of complications early and monitor blood glucose levels, insulin injections and dietary care ${ }^{(17)}$. All these feelings, reactions and care will gradually become part of the routine of people involved in childcare. That is especially true for the diet, insulin applications, and the test for the glycemic level that must be incorporated into daily life. However, the family and caregivers, in general, will never be prepared to deal with and live with all the feelings and other emotional repercussions that the disease mobilizes in people with diabetes ${ }^{(19)}$.

Despite all these challenges, family members must support the needs of children, helping them to manage the disease in 
their daily lives. In the acute stage, family and health professionals should aim to develop strategies that are effective in controlling glycemic disorders. When the health condition is stable, children should be encouraged, whenever possible, to carry out self-care activities independently ${ }^{(20)}$. It is worth mentioning that self-care should be encouraged, always based on the professionals' careful assessment of the child's developmental skills to perform any task, under the supervision of an adult.

Although family members are aware of the importance of glycemic control for maintaining the health and quality of life of their children, they show sadness when using the monitoring device (glucometer). It is as if parents feel their children's pain in their own bodies; thus, they seek compensatory ways to reduce their suffering ${ }^{(21)}$.

The greatest difficulties reported by parents and family members are related to food, such as: saying no to the consumption of some foods considered inappropriate, increased costs with food and difficulty in changing the family's eating habits. Family members are involved in the daily care of children with DM1 and, therefore, face several difficulties, especially when they do not follow treatment. The disease requires children with diabetes, as well as families and health professionals, to join their efforts to achieve good metabolic control and minimize late complications ${ }^{(19)}$.

All families will certainly experience difficult days when taking care of their children with DM1. They may have to adapt to a limited lifestyle, for example, at certain times in the family life cycle. Health professionals are important agents when it is necessary to establish a therapeutic relationship with children and their families; they play a crucial role in hospital and community settings and should provide every opportunity to help children and their families in glycemic control ${ }^{(22)}$.

Despite the difficulties and obstacles encountered in their life habits, families hope for a cure for the disease and present positive perspectives regarding the future of the child with DM1. The search for a cure goes beyond the objective of restoring health to the sick person. It constitutes a kind of social therapy for the child and their family, assuring everyone that the stressors that caused the disease are being eradicated. The family is interested in solving or minimizing the conditions that worsen the disease and, thus, reinforce the factors that allow the health of both the child and the family members to be restored ${ }^{(8)}$.

Health professionals, especially nurses, have a strategic role in health education for children with DM1 and their families. For this reason, they must address not only the physical aspects (blood glucose monitoring, insulin administration, food, and exercise), but also the interaction with the child. They must participate and understand the painful experiences, expanding the understanding of the disease itself and contributing to improve the child's quality of life, particularly in relation to emotional and psychosocial aspects ${ }^{(23)}$.
When the health professional has access to the EM of the patient or his family EM, he collects information that allows understanding the social and individual meanings related to the suffering induced by the disease, the patient's expectations and perspectives regarding treatment, and his goals and concerns. In this context, the professional will be able to direct health care and the educational plan, in order to share a new EM. This makes it possible to organize and alleviate suffering, and to direct health care in a satisfactory manner, especially regarding the treatment and its objectives ${ }^{(24)}$.

\section{FINAL CONSIDERATIONS}

In the search for understanding how children and their families deal with DM1, the explanatory models (EMs) made it possible to perceive that the cause, treatment and prognosis of the disease are interpreted and defined by families in a variety of ways. The use of EMs, especially their popular use, allowed to highlight and organize these different aspects of the experiences of the participants of this study, in order to map the meanings attributed by sick children and their families to their experiences of living with a chronic condition.

In different cultures, each person reacts differently to the diagnosis of a chronic disease such as DM1, resorting to the most diverse explanations for its appearance. Most of the time, the emotional reactions are fear, anxiety, uncertainty, and insecurity. Information and explanations related to the disease must be provided little by little, according to the cultural references the person has. The cultural influence on the treatment of children with diabetes is very intense. Complementary methods are a strategy widely used by families not as a replacement, but coexisting with the conventional treatment. The families, despite having to live with the cultural stigma of the disease and the limitations imposed by the treatment, reported having promising expectations regarding the future of the children with DM1.

The results of this study have the potential to be applied in clinical practice and to motivate future researches. However, it is important to recognize that this study has some limitations, such as the selection of participants from a single health service. This may have made it difficult to include families with different profiles and configurations, for example, single parents and reconstituted families. The knowledge of the EMs, both of children with DM1 and their families, allows for a better management of daily care and, consequently, for a more effective control of the disease.

\section{FUNDING}

This study was funded by the Coordenação de Aperfeiçoamento de Pessoal de Nível Superior - Brazil (CAPES) - Finance Code 001 and the Conselho Nacional de Desenvolvimento Científico e Tecnológico (CNPq), Brazil, Process n 312339/2017-8 and n 423986/2018-0.

\section{REFERENCES}

1. Sociedade Brasileira de Diabetes. Diretrizes da Sociedade Brasileira de Diabetes 2017-2018 [Internet]. São Paulo: Editora Clannad; 2017 [cited 2019 Jan 20]. 1-383 p. Availa-ble from: https://www.diabetes.org.br/profissionais/images/2017/diretrizes/diretrizes-sbd-2017-2018.pdf

2. Queiroz MVO, Brito LMMC, Pennafort VPS, Bezerra FSM. Sensitizing children with diabetes to self-care: Contributions to educational 
practice. Esc Anna Nery. 2016;20(2):337-43. doi: 10.5935/1414-8145.20160046

3. Luca P, Haugrud B, Husband A, Dawrant J, Pacaud D. Evaluation of a diabetes coach program aimed to improve the care of children and youth with type 1 diabetes and with compromised control. Can J Diabetes. 2018;42(5):540-4. doi: 10.1016/j.jcjd.2018.01.005

4. Jönsson L, Lundqvist P, Hallström I. Parents HRQOL, Their satisfaction with care, and children over the age of eight's experiences of family support two years subsequent to the child's diagnosis with type 1 diabetes. Compr Child Adolesc Nurs. 2016;39(4):287-300. doi: $10.1080 / 24694193.2016 .1241837$

5. Lindström C, Åman J, Norberg AL, Forssberg M, Anderzén-Carlsson A. "Mission Im-possible”: the mothering of a child with type 1 diabetes: from the perspective of moth-ers experiencing burnout. J Pediatr Nurs. 2017;36:149-56. doi: 10.1016/j.pedn.2017.06.002

6. Nakamura E, Martin D, Santos JFQ (orgs). Antropologia para Enfermagem. Barueri: Manole; 2009. 144 p.

7. Kleinman A. Patients and healers in the context of the culture: an exploration of the borderland between anthropology, medicine and psychiatry. Berkeley: Univesity of Ca-lifornia Press; 1980. 427 p.

8. Helman CG. Cultura, saúde e doença. 5a. Porto Alegre: Artmed; 2009. 432 p.

9. Lopes M, Nascimento LC, Zago MMF. Paradox of life among survivors of bladder cancer and treatments. Rev EsC Enferm USP. 2016;50(2):22431. doi: $10.1590 /$ S0080-623420160000200007

10. Kleinman A. The Illness Narratives: Suffering, Healing and the Human Condition. Ba-sic Books, editor. New York; 1988. 284 p.

11. Geertz C. A interpretação das culturas. Rio de Janeiro: LTC; 2011. 323 p.

12. Presidência da República (BR). Lei no 8.069, de 13 de julho de 1990. Dispõe sobre o Estatuto da Criança e do Adolescente e dá outras providências [Internet]. Brasília, DF: Diário Oficial da União; 1990[cited 2019 Jan 20]. Available from: http://www.planalto.gov.br/ccivil_03/ leis/l8069.htm

13. Braun V, Clarke V. Using thematic analysis in psychology. Qual Res Psychol. 2006;3(2):77-101. doi: 10.1191/1478088706qp063oa

14. Sand P, Blom MD, Forsander G, Lundin CS. Family dynamics when a child becomes chronically ill: Impact of type 1 diabetes onset in children and adolescents. Nord Psy-chol. 2018;70(2):97-114. doi: 10.1080/19012276.2017.1362990

15. Griggs S, Walker RK. The Role of Hope for Adolescents with a Chronic Illness: An Integrative Review. J Pediatr Nurs. 2016;31(4):404-21. doi: 10.1016/j.pedn.2016.02.011

16. Damsma Bakker A, van Leeuwen RR, Roodbol PF. The spirituality of children with chronic conditions: a qualitative meta-synthesis. J Pediatr Nurs. 2018;43:e106-e113. doi: 10.1016/j.pedn.2018.08.003

17. Iversen AS, Graue M, Haugstvedt A, Råheim M. Being mothers and fathers of a child with type 1 diabetes aged 1 to 7 years: a phenomenological study of parents' experi-ences. Int J Qual Stud Health Well-being. 2018;13(1):1487758. doi: $10.1080 / 17482631.2018 .1487758$

18. Spencer JE, Cooper HC, Milton B. The lived experiences of young people (13-16 years) with Type 1 diabetes mellitus and their parents: a qualitative phenomenological study. Diabet Med. 2013;30(1):e17-24. doi: 10.1111/dme.12021

19. Corrêa A, Franco S, Demário RL. Diabetes Mellitus tipo 1: vivência dos pais em rela-ção à alimentação de seu filho. Alim Nutr [Internet]. 2012[cited 2019 Jan 20];23(4):631-7. Available from: http://docplayer.com.br/20533848-Diabetes-mellitus-tipo-1-vivencia-dos-pais-emrelacao-a-alimentacao-de-seu-filho.html

20. Rostami S, Parsa-Yekta Z, Najafi Ghezeljeh T, Vanaki Z. Supporting adolescents with type 1 diabetes mellitus: a qualitative study. Nurs Health Sci. 2014;16(1):84-90. doi: 10.1111/nhs.12070

21. Cruz DSM, Collet N, Andrade EMC, Nóbrega VM, Nóbrega MML. Mothers of expe-riences in diabetic child. Esc Anna Nery. 2017;21(1). doi: $10.5935 / 1414-8145.20170002$

22. Kenny J, Corkin D. A children's nurse's role in the global development of a child with diabetes mellitus. Nurs Child Young People. 2013;25(9):22-5. doi: 10.7748/ncyp2013.11.25.9.22.e204

23. Sparapani VC, Jacob E, Nascimento LC. What is it like to be a child with type 1 diabe-tes mellitus? Pediatr Nurs. 2015;41(1):17-22. doi: $10.1017 /$ S0265052509090098

24. Kleinman A, Eisenberg L, Good B. Culture, illness, and care: clinical lessons from an-thropologic and cross-cultural research. Ann Intern Med. 1978;88(2):251-8. doi: 10.7326/0003-4819-88-2-251 